\title{
Ferramenta de geração automática de roteiros RPGs para auxílio no ensino de História
}

\author{
Alex Bohn Angelo ${ }^{1}$ <alexangelo@ gmail.com> \\ Fabiana Lorenzi ${ }^{1}<$ fabilorenzi@gmail.com> \\ Marlise Geller ${ }^{2}<$ marlise.geller@gmail.com> \\ ${ }^{1}$ Universidade Luterana do Brasil (ULBRA) - Curso de Ciência da Computação - Canoas - RS \\ ${ }^{2}$ Universidade Luterana do Brasil (ULBRA) - PPGECIM - Canoas - RS
}

\begin{abstract}
This paper presents the development of an intelligent tool able to generate narrative structures of RPG adventures to be used by teachers as a teaching tool. The tool uses the narrative structure known as Hero's Journey to create scripts of RPG's adventures based on the subject chosen by the teacher without the need that he has knowledge of RPG, providing an alternative and ludic teaching tool for teachers. The tool was validated for high school students.
\end{abstract}

Resumo. Este artigo apresenta o desenvolvimento de uma ferramenta inteligente capaz de gerar estruturas narrativas de aventuras de RPG para ser utilizado por professores como instrumento de ensino. A ferramenta utiliza a estrutura narrativa conhecida como Jornada do Herói para criar roteiros de aventura baseados na matéria escolhida pelo professor sem ter a necessidade de que ele tenha conhecimento sobre RPG, proporcionado uma ferramenta alternativa e lúdica de ensino para os professores. A ferramenta foi validada em turmas de ensino médio na disciplina de história.

\section{Introdução}

Atualmente os professores precisam fazer um esforço muito grande para terem a atenção dos alunos, dada a presença de celulares e tablets em sala de aula. É preciso inovar e por este motivo diversos métodos foram criados pelos educadores como proposta para tornar a aula mais atrativa para os alunos. Uma destas estratégias de ensino foi popularizada como gamification. Este método usa a técnica de dar caráter de jogo a uma atividade de ensino através de mecânicas de jogo envolvendo pontos, dados e cartas. Aplicando esta proposta, alguns professores recorrem a métodos de ensino lúdicos, utilizando, em sala de aula, jogos de tabuleiro e Role Playing Games (RPG) como ferramenta para apresentar o conteúdo. Estas atividades lúdicas facilitam o processo de aprendizado dos alunos, pois vinculam o ato de estudar e aprender a um jogo ou brincadeira, que além de aumentar o foco dos alunos, faz da atividade mais divertida. As atividades lúdicas ajudam no desenvolvimento intelectual e cognitivo, promovendo processos de socialização e descoberta do mundo para crianças e adolescentes.

Este artigo apresenta uma ferramenta capaz de gerar automaticamente um roteiro de RPG para que o professor possa utilizar em sala de aula. Através da 
ferramenta o professor é capaz de utilizar o seu conhecimento na disciplina na criação de um roteiro de RPG que pode ser aplicado em sala de aula como uma atividade lúdica.

\section{Referencial Teórico}

\subsection{Role Plaiyng Game}

Role Playing Game, ou simplesmente RPG, que em português significa "Jogo de Representação de Papéis", é um jogo de narrativa compartilhada onde alguns jogadores criam e interpretam personagens que vão moldando uma história apresentada por um jogador que recebe a alcunha de narrador, também chamado mestre de jogo. $\mathrm{O}$ mestre de jogo é responsável por apresentar aos jogadores o mundo onde eles vivem, através da estrutura narrativa para os jogadores por meio de desafios, encontros e acontecimentos. Porém, no RPG, os jogadores, diferentes dos atores, interpretam seus personagens tomando decisões, enfrentado desafios ou simplesmente tomando outro caminho, assim criando a história juntamente com o narrador.

\subsection{RPG e a Educação}

As dificuldades encontradas pelos educadores na busca pela atenção dos alunos, segundo Vieira (2012) são, em parte, reflexos do modelo de ensino atual, que se encontra severamente desatualizado. A cultura geral induz o aluno a ter antipatia com a escola e ter um preconceito com relação as suas atividades. Uma das primeiras propostas de utilização de jogos consistia em transformar o jogo em parte das atividades escolares, tendo em seu contexto conteúdos relevantes de todas as áreas, apresentado o conteúdo de uma forma lúdica em um processo de repetições diversas. No trabalho apresentado em Maike et al (2011), os autores mostram um estudo sobre os requisitos necessários para a utilização de RPG em escolas públicas para o ensino fundamental, utilizando RPG como ferramenta pedagógica em sala de aula.

A utilização de RPG, além de resgatar a tradição oral de contar histórias, oferece o estímulo para aqueles que estão em fase de aprendizagem Bittencourt e Giraffa (2003). Para se jogar RPG é necessário criar uma forma estruturada. Muitos narradores de RPG já possuem o conhecimento da criação de estruturas narrativas muito bem desenvolvidas através da prática do jogo. Segundo Campbell (1995), todas as histórias estão ligadas por um fio condutor comum, independente de serem mitos antigos, contos de fadas ou blockbusters do cinema e seria possível estruturar qualquer história a partir do roteiro básico da "Jornada do Herói", além de poder fragmentar as histórias e identificar nelas cada passo que constitui a "Jornada". A história é dividida em três partes: a Apresentação, o Conflito e a Resolução. Neste trabalho, o modelo criado por Campbell serve de estrutura para a criação dos modelos narrativos. Todos os roteiros criados pela ferramenta utilizarão o modelo da "Jornada do Herói" como coluna vertebral para sua estrutura narrativa.

\section{Desenvolvimento da ferramenta}

Este trabalho apresenta o desenvolvimento de uma ferramenta capaz de minimizar a curva de aprendizado necessária para aplicação do RPG no ensino, facilitando o processo de gamificação do conteúdo, criando um roteiro e servindo de diretor de cena 
para o professor. Além disto, a ferramenta permite montar personagens para os jogadores e possibilita a troca de experiência entre usuários através da funcionalidade de recuperar roteiros pré-criados por outros usuários.

A ferramenta é capaz de adaptar a estrutura narrativa para cada tema que o professor queira lecionar. Isso se dá por meio de um conjunto de atributos com diferentes opções que moldam a estrutura. Os valores dos atributos serão obtidos por meio da caracterização do tema feita pelo professor. A ferramenta oferece também, além da possibilidade da criação, a opção do acesso rápido a partidas de RPG préroteirizadas por outros usuários. A interface da ferramenta foi desenvolvida na linguagem de programação PHP e com HTML através da ferramenta Net-Beans e do editor Sublime Text2. A estrutura de banco de dados desta ferramenta, que armazenará a base de conhecimento, as estruturas narrativas e as fichas de personagens foi implementada em MySQL. Para a criação do roteiro, a ferramenta conta com um módulo inteligente, que através de regras, escolhe os componentes que serão incluídos em cada roteiro.

\subsection{Módulo Inteligente}

O módulo inteligente da ferramenta é responsável pela geração do roteiro de RPG conforme a necessidade indicada pelo professor. Para que fosse possível este desenvolvimento, o primeiro passo necessário foi a Aquisição de Conhecimento, onde especialistas da área de RPG foram entrevistados com o objetivo de obter o conhecimento de como um roteiro deve ser criado.

Para que a ferramenta fosse capaz de capturar as necessidades do professor para formular o roteiro que dará origem ao enredo, foi necessário fazer uma análise do conjunto de características que relacionadas ao assunto a ser roteirizado. Para formular este conjunto de características essenciais para a geração do roteiro foi utilizado o método de entrevista estruturada com especialistas. As entrevistas foram realizadas com cinco escritores (Carolina Munhoz, Raphael Draccon e Leonel Caldela, Gustavo Brauner e Rafael Rocha). Com o conteúdo das entrevistas foi criada uma lista de palavras relacionadas a estes temas. Através da lista de palavras obtida foram criadas as palavras-chaves, chamadas de tags, que servem para caracterizar cada um dos atributos da narrativa, cada tipo de personagem e cada tipo de história que pode ser criada pela ferramenta.

Todos os atributos, personagens, temas e climas que existem na ferramenta receberam um cadastro que quantificou seu valor diante cada uma das tags. Este valor pode ter sido 0 , que indica que a tag não o caracteriza, ou 1 que significa que ela o caracteriza. Este valor também pode ter valor maiores, como $3 \mathrm{em}$ casos específicos (quando a tag Idade Média precisa caracterizar o tempo Idade Média, por exemplo, pois neste caso a quantidade poderia determinar a precisão da informação). Com as tags devidamente cadastradas o módulo inteligente torna-se devidamente apto a suas duas principais funções: inserção das instruções para a criação da estrutura narrativa e as instruções para Gamificação. 


\subsection{EstruturaNarrativa}

O enredo será criado pelo professor através do seguimento de instruções dadas pelo módulo inteligente para cada cena da história. Cada uma destas cenas é chamada no roteiro de Ato. O módulo inteligente utiliza uma base de regras, que foram criadas a partir da etapa de aquisição de conhecimento, para definir qual cena o roteiro deve conter. Por exemplo, tendo o professor escolhido tags como "Guerra", "Revolução" e "Política", a ferramenta sugere o ato "Travessia do Primeiro Limiar" como o mais adequado para a história. Cada uma destas opções de descrição de cena que cada Ato possui é chamada na ferramenta de Atributo.

Alguns Atos possuem, além dos atributos, os subatributos. Os subatributos são uma especificação do atributo com o fim de caracterizar melhor um problema ou fato. Quando, por exemplo, o Ato "Provação Suprema" recebe o Atributo "Desafio", é necessário informar o tipo de desafio que o professor poderá incluir naquela cena. Este tipo poderá variar de acordo tanto com as tags preenchidas pelo professor quanto o próprio atributo. $\mathrm{O}$ cadastro dos subatributos é fruto do entrelace de duas partes do módulo inteligente, a que propõe a criação de uma narrativa e a que propõe a aplicação dos conceitos de gamificação. Pelas características destes subatributos, a ferramenta oferece ao autor do novo enredo a opção de buscar uma segunda sugestão para cada subatributo. Caso ele deseje usar aquele elemento em sua narrativa ou não, a fim de que nenhum subatributo entre em desacordo com os métodos de ensino do professor. Este método tratará apenas opções questionáveis da classificação, como, por exemplo, a inserção de um combate na história ou substituí-lo por um plano para ajudar a vencer a guerra sem violência direta.

\subsection{Gamificação}

O processo de gamificação é uma das partes mais importantes do módulo inteligente e afeta diretamente todo o roteiro. Ao criar os personagens, o módulo inteligente utiliza métodos de arquétipos. Este processo de gamificação resulta do cruzamento das informações das tags escolhidas para caracterizar o enredo e dos atributos selecionados para compor as instruções de cada uma das cenas. Através das regras existentes na base, a ferramenta seleciona quais desafios serão os mais adequados para o roteiro que está sendo gerado.

\section{Implementação}

A ferramenta é apresentada ao professor no formato de web-site sem requisitar login ou senha. Ao optar por criar um enredo novo, o professor é conduzido por telas que possibilitam a compreensão do tema pelo módulo inteligente e a geração do produto final, um arquivo em extensão PDF, disponível para download na forma de um roteiro, pronto para ser jogado. A partir do cadastro do professor, ele indica o título de seu projeto e quantos serão os personagens jogadores que ele deseja, além de descrever o objetivo deste roteiro.

A ferramenta apresenta uma lista de características disponíveis, ou seja, as tags que auxiliam a ferramenta a compreender do que trata o tema. Com base nas tags selecionadas, a ferramenta dispara as regras com o objetivo de encontrar em cada lacuna 
do projeto de enredo a opção de atributo mais adequada para o enredo e que tipos de desafios se encaixam neste enredo para promover a gamificação. Após a escolha das tags, a ferramenta cria a lista de personagens para a história e cadastra as instruções mais pertinentes para cada Ato do roteiro. Cada personagem receberá uma ficha, contendo seus dados para fins de jogo como habilidades, perícias e características, além de um espaço para história. Estas fichas de personagens são o instrumento que define o personagem que cada jogador interpreta em uma partida de RPG. Elas serão utilizadas pelos grupos de alunos, sendo cada um deles o intérprete deste personagem na história.

\section{Validação}

A ferramenta foi validada através de oficinas realizadas em um Colégio Estadual na disciplina de História. A validação foi realizada em duas etapas: primeiro, o professor foi apresentado e instruído sobre o uso da ferramenta e efetuou testes onde gerou uma aventura de RPG para ser aplicada em sua disciplina; segundo, a aventura de RPG gerada pelo professor através da ferramenta foi aplicada em sala de aula (o professor aplicou a aventura em 2 turmas de 20 ano do Ensino Médio). O método que foi utilizado para a validação justificou a necessidade do desenvolvimento em uma plataforma que funcione em qualquer sistema operacional devido ao fato de que as escolas da rede pública, como uma das quais foi realizada a oficina, utilizam sistema Linux. Após a aplicação da aventura nas turmas, os alunos foram convidados a responder um questionário para análise dos resultados da utilização do roteiro gerado pela ferramenta. Todos os alunos demonstraram ter gostado da aplicação do conteúdo da matéria neste formato RPG, não tendo rejeição e $90 \%$ dos alunos solicitaram que esta atividade fosse repetida nas disciplinas de geografia e literatura.

\section{Conclusão}

A utilização do RPG como um instrumento de ensino é possível sem a necessidade do conhecimento sobre o jogo por parte do professor e com poucos recursos computacionais. Através da validação realizada em sala de aula, foi possível ver que a aplicação de métodos lúdicos pode ser uma excelente alternativa para tornar mais atrativo o ensino de alguns conteúdos.

\section{Referências}

Bittencourt, J.R. e Giraffa, L.M. (2003) "Modelando Ambientes de Aprendizagem Virtuais Utilizando Role-Playing Games". In: XIV Simpósio Brasileiro de Informática na Educação, p. 683-692.

Campbell, Joseph. (1995) O Herói de Mil Faces. São Paulo, Editora Cultrix/Pensamento, p. 416.

Maike, Vanessa; Miranda, Leonardo; Baranauskas, M. Cecília. (2011) "Investigando sobre Requisitos para um Jogo de RPG com Professores de uma Escola Pública de Ensino Fundamental." Anais do Simpósio Brasileiro de Informática na Educação. Vol. 1. No. 1..

Vieira, Matheus. (2012) RPG \& Educação. Curitiba, Editora Íthala, p. 143. 